\title{
The degree of social difficulties experienced by cancer patients and their spouses
}

Takashi Takeuchi $^{1^{*}}$, Kanako Ichikura ${ }^{2,5}$, Kanako Amano $^{2}$, Wakana Takeshita ${ }^{2,3}$ and Kazuho Hisamura ${ }^{4}$

\begin{abstract}
Background: Although recent studies have increasingly reported physical and psychological problems associated with cancer and its treatment, social problems of cancer patients and their families have not been sufficiently elucidated. The present study aimed to identify cancer-associated social problems from the perspectives of both patients and their spouses and to compare and analyze differences in their problems.

Methods: This was a cross-sectional internet-based study. Subjects were 259 patients who developed cancer within the previous five years and 259 patients' spouses; the data were derived from two surveys in 2010 (patients) and 2016 (spouses) whose participants were not part of the same dyad but matched by propensity scores, estimated for age, sex, and the presence or absence of recurrence. We investigated the social difficulties of cancer patients and patients' spouses. Regarding social difficulties experienced by cancer patients and spouses, the 60 patient survey items were categorized into 14 labels by the Jiro Kawakita (KJ) method, which is a qualitative synthesis method developed by Kawakita to classify categorical data.
\end{abstract}

Results: Although patients had higher scores on most subcategories, young spouses aged 39 or younger and female spouses had difficulty scores as high as the corresponding patients on many subcategories.

Conclusion: Health care providers should show sufficient concern for both patients and their spouses, particularly young and female spouses.

Keywords: Social problems, Cancer, Patients, Spouses, Difficulties, Internet survey

\section{Background}

The diagnosis and treatment of cancer often not only impose physical and mental distress on patients, but also substantially change their daily lives. Consequently, patients often face problems in various aspects of social life, such as family life, relationships with people around them, work, income, leisure activities, and relationships with health care providers [1-5]. Because of current advances in medical technology and availability of outpatient care, the length of hospital stay has been reduced for cancer patients. Because terminal home care is expected to be further promoted in the future, it is assumed that the main site of cancer patient care will increasingly be shifted from

\footnotetext{
* Correspondence: okashi@bf6.so-net.ne.jp

${ }^{1}$ Section of Psychiatry and Behavioral Sciences, Graduate School of Medical and Dental Sciences, Tokyo Medical and Dental University, 1-5-45 Yushima, Bunkyo-ku, Tokyo 113-8519, Japan

Full list of author information is available at the end of the article
}

hospitals to homes. Under these circumstances, cancer patients and their families are required to deal with various social problems arising as the disease and treatment progress.

Recent studies have increasingly reported on physical problems associated with cancer and its treatment and psychological problems, such as anxiety and depression. As several studies have indicated that social problems experienced by cancer patients have an important impact on their mental health and quality of life [6-10], the need for support for their social problems, as well as the mental care of patients, has been increasingly recognized. However, the reality of the social problems experienced by the families who support cancer patients has not yet been sufficiently understood. Spouse caregivers provide the most extensive and comprehensive care, maintain the caregiver role longer, tolerate greater levels of disability than other

(c) The Author(s). 2018 Open Access This article is distributed under the terms of the Creative Commons Attribution 4.0 International License (http://creativecommons.org/licenses/by/4.0/), which permits unrestricted use, distribution, and reproduction in any medium, provided you give appropriate credit to the original author(s) and the source, provide a link to the Creative Commons license, and indicate if changes were made. The Creative Commons Public Domain Dedication waiver (http://creativecommons.org/publicdomain/zero/1.0/) applies to the data made available in this article, unless otherwise stated. 
caregivers, and experience more severe lifestyle adjustments [11]. The spouse is the primary informal caregiver for cancer patients, and can experience high levels of stress, potential burnout, depressive symptoms, marital distress, poor health, and unmet needs [12, 13].

Thus, the present study aimed to investigate the degree of social difficulties experienced by cancer patients and their spouses, to identify cancer-associated social problems from the perspectives of both patients and their spouses, and to compare and analyze differences in their problems.

\section{Methods}

\section{Study design and subjects}

This is a cross-sectional study using internet-based surveys. The internet survey company we used is a Japanese company specializing in academic research. For the patient survey, in January 2010, we screened all registered members of the panel of internet-survey company A and selected those who developed cancer within the previous 5 years and experienced social problems. For the spouse survey, in the same manner in November 2016, we selected spouses of patients who developed cancer within the previous 5 years. Subjects were 259 patients and 259 patients' spouses and all cancer types were selected.

\section{Assessment indicators \\ The degree of social difficulties experienced by cancer patients and spouses}

The list of social difficulties experienced by cancer patients and spouses was prepared based on a list of patients' problems developed from the results of a qualitative survey asking, "What bothers you as a cancer patient?" in our previous study [14]. In this previous study, the list of social difficulties of patients was developed through discussion between an oncology social worker and a psychiatrist who reviewed articles published in Japan and other countries on social problems, distress, stressors, and patients' unmet needs. This list contains 60 items, on which patients are asked to answer the question, "Have you ever experienced any difficulty concerning the following matters at home, at work, or in your community because of your disease and treatment?" by choosing one of the following 6 options: It has been very difficult; it has been fairly difficult; it has not been very difficult; it has never been difficult; I do not know; and not applicable (Table 1). In the present study, to investigate difficulty perceived by spouses regarding the social problems of patients, we asked spouses to answer the question, "Have you ever experienced any difficulty concerning the following matters at home, at work, or in your community because of the disease (cancer) and treatment of the patient (your spouse)?" on the 60 items in the same manner. To use the 60 items for the spouse survey, the word "you" was replaced with "the patient," and "your family" with "you." For both the patient and spouse surveys, the options, "It has never been difficult," "I do not know," and "not applicable," were combined as "It has never been difficult," and the survey results were statistically analyzed as those of a four-choice survey: "It has never been difficult (0 points)," "It has not been very difficult (1 point)," "It has been fairly difficult ( 2 points)," and "It has been very difficult ( 3 points)." Furthermore, in the present study, these 60 items were first classified by the Jiro Kawakita (KJ) method (Affinity Diagram). The KJ method is a qualitative synthesis method developed to classify categorical data by Kawakita [15, 16]. Specifically, two clinical psychologists independently classified the 60 items. Then, items with mismatched labels were labeled through discussion between the psychologists. Next, a group led by a psychiatrist that included clinical psychologists routinely involved in supporting cancer patients reviewed the list of labeled items, made corrections to the arrangement of items and wording of the labels, and finalized the labels. Second, these labels were used as the subcategories of this list. For each subcategory, $\alpha$ coefficient was calculated to evaluate internal consistency. Finally, scores on each subcategory were calculated by dividing the total score by the number of items in each subcategory. This research was not a qualitative study. To adjust the scale of the social problems created by Hisamura et al., we used the KJ method which is a qualitative synthesis method. We chose this approach because we study social systems and social problems peculiar to Japan that cannot be measured by existing social problem scales.

\section{Demographic and clinical variables of the patients}

The demographic and clinical data were collected from self-administered surveys of all the study subjects. Specifically, the cancer patients were asked to answer multiplechoice questions on their sex, age, the presence or absence of recurrence, cancer sites, treatment, treatment regimens, state of treatment, academic background, and occupation.

\section{Analysis methods}

First, sex, age group, and presence or absence of recurrence were selected as covariates that should be adjusted based on clinical judgment, and propensity scores for these covariates were estimated using logistic regression models. Based on the calculated propensity scores, the patient and spouse groups were matched in a 1:1 ratio using nearest neighbor matching by sampling without replacement. Frequency distributions of the matched data were generated for background factors in each group to assess the balance among the covariates.

Second, differences in the degree of social difficulties experienced by the patient and spouse group were analyzed by independent two-sample $t$-tests. Furthermore, 
Table 1 Classification of difficulties according to the Jiro Kawakita method

Label
1. Difficulty in performing activities of daily
living
$(a=.847)$

2. Difficulty in seeking expert advice on the disease state and treatment

$(a=.909)$

3. Complaints with health care providers

$(a=.932)$

4. Lack of information on treatment and disease state

$(a=.937)$

5. Lack of information on self-care

$(a=.909)$

6. Conflict over family relationships

$(a=.898)$

7. Concerns for family members

$(a=.897)$

\section{Item}

Outpatient examinations and regular hospital visits

Going out and transportation methods (including the use of public transportation systems)

Taking care of myself (e.g., eating, bathing, toileting, and dressing)

Household chores (e.g., house cleaning, laundry, meal preparation, and grocery shopping)

Sex life

Your disease and treatment have made hobbies, pastimes, and social activities less enjoyable.

Admission to, discharge from, and transfer from a hospital

Consulting a specialist other than your attending physician about your disease state and treatment You and your family cannot receive necessary psychological counseling.

In case of sudden deterioration of your physical condition, there is no guarantee that you can immediately consult any doctors at the hospital where you are currently treated (or your neighborhood hospitals or clinics).

Neither you nor your family have any primary care physicians at hospitals or clinics whom you can consult whenever necessary.

Selection of a hospital (or a physician) that will provide treatment and examinations to you

Health care providers (e.g., physicians and nurses) do not promptly deal with your physical problems.

Health care providers do not recognize your emotional problems or show any concern.

Health care providers (e.g., your attending physician, physicians at other departments, your primary care physician, and nurses) do not sufficiently communicate with each other to arrange your treatment and care.

Before you choose treatment, health care providers do not sufficiently explain the beneficial and adverse effects of each treatment strategy.

Health care providers do not sufficiently explain the policy or plan of future treatment.

You cannot talk frankly with your attending physician.

You cannot obtain enough information on the methods and contents of tests.

You do not know how to collect information on the treatment of your disease.

You cannot obtain enough information on various treatment methods.

You cannot obtain enough information on complementary and alternative medicine (methods that are not regarded as standard treatment at present, such as health food, hot springs, and Qigong).

You cannot obtain enough information on palliative medicine and care that alleviates pain and distress.

You cannot obtain enough information on your current disease state and prognosis.

You cannot obtain enough information on how to treat adverse effects of treatment that you receive and symptoms of your disease.

You cannot obtain enough information on what to keep an eye on in future life.

You cannot obtain enough information on appropriate nutrition and dietary patterns.

You cannot obtain enough information on how to deal with anxiety and depression.

Your family do not understand your disease or treatment well and sufficiently cooperate with you.

Your views on your disease and treatment differ from the views of your family.

Talking with your family about your disease

Relationship and communication with your spouse

Care of your family (e.g., care of your parents, child-rearing, and nursing by your spouse)

Burden on your family

You cannot sufficiently take care of anxiety or concerns that your family have.

Support offered to your family (e.g., help from people around you or public services) is insufficient. 
Table 1 Classification of difficulties according to the Jiro Kawakita method (Continued)

\begin{tabular}{|c|c|}
\hline Label & Item \\
\hline & You cannot sufficiently perform your role at home. \\
\hline & Your family are overly worried about you. \\
\hline 8. Difficulty in planning life & Planning future life of you and your family \\
\hline$(a=.594)$ & Developing your plans for marriage, pregnancy, and delivery \\
\hline $\begin{array}{l}\text { 9. Conflict over relationships with non-family } \\
\text { members }\end{array}$ & Relationships and communication with your friends and people close to you \\
\hline \multirow[t]{2}{*}{$(a=.902)$} & Relationships and communication with your neighbors \\
\hline & Talking about your disease with people at work or in other social occasions \\
\hline $\begin{array}{l}\text { 10. Difficulty in adapting to changes in the } \\
\text { social environment }\end{array}$ & You have been discriminated because of your disease. \\
\hline \multirow[t]{2}{*}{$(a=.804)$} & The attitudes of people around you have changed after the onset of your disease. \\
\hline & Your looks (appearance) have changed. \\
\hline 11. Lack of local support services & You do not have any opportunity to talk with people with similar experiences. \\
\hline \multirow[t]{2}{*}{$(a=.902)$} & You are lonely. \\
\hline & $\begin{array}{l}\text { You do not have anyone with whom you can consult or have access to services that offer } \\
\text { consultation for the disease and medical care. }\end{array}$ \\
\hline 12. Difficulty in solving work-related issues & It is difficult to return to and continue work (or study if you are a student). \\
\hline \multirow[t]{4}{*}{$(\mathrm{a}=.892)$} & It is difficult to take a day off from work (or school if you are a student) for treatment. \\
\hline & Your disease has adversely affected your promotion at work. \\
\hline & You have been demoted or transferred to an unimportant position at work. \\
\hline & $\begin{array}{l}\text { You have been asked to retire or fired at work (In case of being self-employed, you have closed } \\
\text { your business). }\end{array}$ \\
\hline 13. Difficulty in making financial arrangements & Medical and living expenses during treatment \\
\hline \multirow[t]{2}{*}{$(a=.824)$} & The use of financial services (e.g., loan, medical insurance, and life insurance) \\
\hline & Management of the properties of yours and your family \\
\hline $\begin{array}{l}\text { 14. Lack of information on welfare services } \\
\text { available during treatment }\end{array}$ & $\begin{array}{l}\text { You cannot obtain enough information on available welfare services and systems (e.g., nursing-care } \\
\text { insurance and welfare services for people with disabilities). }\end{array}$ \\
\hline \multirow[t]{2}{*}{$(a=.925)$} & $\begin{array}{l}\text { You cannot obtain enough information on available home-based medical care services (e.g., home- } \\
\text { visit medical treatment and nursing). }\end{array}$ \\
\hline & $\begin{array}{l}\text { You cannot obtain enough information on support for your medical care (e.g., wig, elastic stocking, } \\
\text { wheelchair, and special bed). }\end{array}$ \\
\hline
\end{tabular}

$t$-tests were also performed to analyze differences in the degree of the difficulties for the following combinations of subgroups: between the younger generation ( $\leq 39$ years) and middle-aged and older generation ( $\geq 40$ years), and between male patients/female spouses and female patients/ male spouses.

The significance level was set at $5 \%$. SPSS for Windows 23 was used to perform statistical analyses.

\section{Results}

Subcategories of social difficulties experienced by cancer patients and spouses according to the $\mathrm{KJ}$ method (affinity diagram)

According to the $\mathrm{KJ}$ method, social difficulties were classified into 14 labels. Specifically, the 60 items were classified into the following subcategories: "difficulty in performing activities of daily living," "difficulty in seeking expert advice on the disease state and treatment," "complaints with health care providers," "lack of information on treatment and disease state," "lack of information on self-care," "conflict over family relationships," "concerns for family members," "difficulty in planning life," "conflict over relationships with non-family members," "difficulty in adapting to changes in the social environment," "lack of local support services," "difficulty in solving work-related issues," "difficulty in making financial arrangements," and "lack of information on welfare services available during treatment." The $\alpha$ coefficients for the internal consistency of the subcategories are shown in Table 1.

\section{Matching for the characteristics and propensity scores of the subjects}

When the patients and spouses were matched based on the propensity scores calculated from logistic regression 
models, 259 subjects were selected from each of the patient and spouse groups (Fig. 1). Table 2 shows the frequency distributions of the covariates and other background factors for each group. Regarding the covariates, the frequency distributions of sex, age group, and presence or absence of recurrence were completely matched between the patient and spouse groups, confirming that the groups were well balanced and matched. Regarding other background factors, cancer sites varied in both the patient and spouse groups, while most participating patients and patients of most participating spouses were being treated or followed up after the completion of treatment.

Differences in the degree of social difficulties experienced by the patient and spouse groups

The $t$-test results showed that the degree of "difficulty in seeking expert advice on the disease state and treatment" was comparable between the patient and spouse groups $(t=.75, p=.45)$, whereas the degree of difficulty for all the other subcategories was higher in the patient than the spouse group (Table 3).

Meanwhile, in the younger subgroups ( $\leq 39$ years), the mean difficulty scores in the spouses increased for all subcategories except "difficulty in adapting to changes in the social environment." The degree of difficulty was comparable between patients and spouses (Table 4).

In the male patient/female spouse subgroups, the mean difficulty scores in the spouses increased for the following subcategories: "difficulty in seeking expert advice on the disease state and treatment," "complaints with health care providers," "lack of information on treatment and disease state," "lack of information on self-care," "concerns for family members," "lack of local support services," "difficulty in making financial arrangements," and "lack of information on welfare services available during treatment." The degree of difficulty for these subcategories was comparable between patients and spouses (Table 5).

\section{Discussion}

In the present study, difficulty for cancer patients and their spouses in dealing with social problems was investigated and compared. Because there have been few studies that directly examined these problems, we would like to discuss them in associations with their consequences, such as depression, distress, morbidity, burden, unmet need, and decreased quality of life.

\section{Comparison of difficulty between patients and spouses}

The degree of difficulty was higher in the patient than the spouse group for all subcategories except "difficulty in seeking expert advice on the disease state and treatment (lack of opportunities to consult for patient transfer arrangement, hospital selection, second opinion, psychological counseling, etc.)." Patients and partners are interdependent in that cancer impacts on their shared life, both emotionally and practically. However, no conclusion has been reached on whose distress is more severe because there are conflicting reports. While some reports indicate that distress severity is comparable between patients and their spouses or partners, other reports indicate that patients' distress is more severe than that of their spouses or partners, and there are even reports indicating that distress of spouses or partners is more severe than that of patients [17]. Hodges et al. [18] investigated mental distress of spouses or partners of patients over the

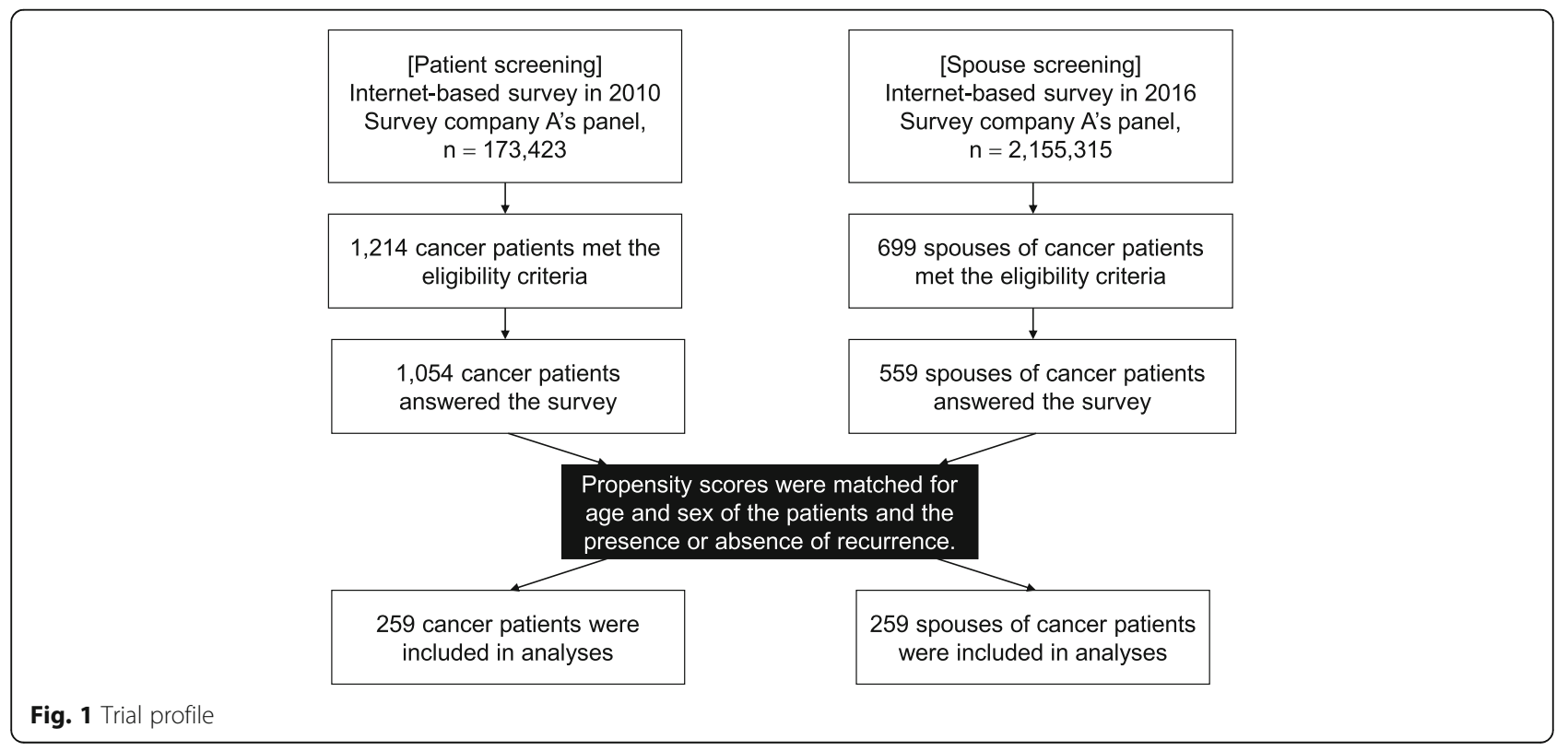


Table 2 Demographic and clinical data

\begin{tabular}{|c|c|c|}
\hline & $\begin{array}{l}\text { Patients } \\
n(\%)\end{array}$ & $\begin{array}{l}\text { Spouses } \\
n(\%)\end{array}$ \\
\hline \multicolumn{3}{|l|}{ Patients' sex } \\
\hline Men & $128(49.4)$ & $128(49.4)$ \\
\hline Women & $131(50.6)$ & $131(50.6)$ \\
\hline \multicolumn{3}{|l|}{ Patients' age } \\
\hline 20-29 years & $11(4.2)$ & $11(4.2)$ \\
\hline 30-39 years & $44(17.0)$ & $44(17.0)$ \\
\hline 40-49 years & $67(25.9)$ & $67(25.9)$ \\
\hline $50-59$ years & $85(32.8)$ & $85(32.8)$ \\
\hline 60- years & $52(20.1)$ & $52(20.1)$ \\
\hline \multicolumn{3}{|l|}{ The presence or absence of recurrence } \\
\hline Primary occurrence & $62(23.9)$ & $62(23.9)$ \\
\hline Recurrence & $197(76.1)$ & $197(76.1)$ \\
\hline \multicolumn{3}{|l|}{ Cancer site (including duplicates) } \\
\hline Lung cancer & $34(13.1)$ & $29(11.2)$ \\
\hline Prostate cancer & $25(9.7)$ & $13(5.0)$ \\
\hline Renal cancer & $19(7.3)$ & $6(2.3)$ \\
\hline Bladder cancer & $19(7.3)$ & $5(1.9)$ \\
\hline Testicular cancer & $15(5.8)$ & $5(1.9)$ \\
\hline Gastric cancer & $48(18.5)$ & $31(12.0)$ \\
\hline Esophageal cancer & $20(7.7)$ & $5(1.9)$ \\
\hline Colorectal cancer & 49 (18.9) & $50(19.3)$ \\
\hline Liver cancer & $17(6.6)$ & $6(2.3)$ \\
\hline Gallbladder cancer & $13(5.0)$ & $2(0.8)$ \\
\hline Pancreatic cancer & $12(4.6)$ & $3(1.2)$ \\
\hline Breast cancer & $79(30.5)$ & $63(24.3)$ \\
\hline Thyroid cancer & $20(7.7)$ & $6(2.3)$ \\
\hline Head and neck/oral cancer & $11(4.2)$ & $7(2.7)$ \\
\hline Uterine cancer & $27(10.4)$ & $12(4.6)$ \\
\hline Ovarian cancer & $18(6.9)$ & $3(1.2)$ \\
\hline Leukemia & $17(6.6)$ & $8(3.1)$ \\
\hline Malignant lymphoma & $18(6.9)$ & $15(5.8)$ \\
\hline Malignant bone tumor & $10(3.9)$ & $1(0.4)$ \\
\hline Brain tumor & $17(6.6)$ & $1(0.4)$ \\
\hline Skin cancer & $14(5.4)$ & $2(0.8)$ \\
\hline Cancer of unknown primary & $5(1.9)$ & $0(0.0)$ \\
\hline Others & $18(6.9)$ & $24(9.3)$ \\
\hline \multicolumn{3}{|l|}{ Treatments (including duplicates) } \\
\hline Surgery & $217(83.8)$ & $208(80.3)$ \\
\hline Radiation therapy & $92(35.5)$ & $95(36.7)$ \\
\hline Chemotherapy & $147(56.8)$ & $101(39.0)$ \\
\hline \multicolumn{3}{|l|}{ Patients' treatment status } \\
\hline $\begin{array}{l}\text { Patients are currently under cancer } \\
\text { treatment }\end{array}$ & $138(53.3)$ & $118(45.6)$ \\
\hline
\end{tabular}

Table 2 Demographic and clinical data (Continued)

\begin{tabular}{|c|c|c|}
\hline & $\begin{array}{l}\text { Patients } \\
n(\%)\end{array}$ & $\begin{array}{l}\text { Spouses } \\
n(\%)\end{array}$ \\
\hline $\begin{array}{l}\text { Cancer was cured, and treatment } \\
\text { was completed. }\end{array}$ & $90(34.7)$ & $120(46.3)$ \\
\hline $\begin{array}{l}\text { Cancer is not cured, but aggressive } \\
\text { treatment has been completed. }\end{array}$ & $12(4.6)$ & $12(4.6)$ \\
\hline Others & $19(7.3)$ & $9(3.5)$ \\
\hline \multicolumn{3}{|l|}{ Academic background } \\
\hline Junior high-school graduates & $8(3.1)$ & $10(3.9)$ \\
\hline High-school graduates & $68(26.3)$ & $73(28.2)$ \\
\hline $\begin{array}{l}\text { Vocational school/junior college } \\
\text { graduates }\end{array}$ & $53(20.5)$ & $65(25.1)$ \\
\hline Four-year college graduates & $130(50.2)$ & $111(42.9)$ \\
\hline \multicolumn{3}{|l|}{ Work } \\
\hline Full-time employment & $98(37.8)$ & $140(54.1)$ \\
\hline Part-time employment & $28(10.8)$ & $35(13.5)$ \\
\hline Full-time housewife & $37(14.3)$ & $55(21.2)$ \\
\hline $\begin{array}{l}\text { Leave of absence because of the } \\
\text { disease }\end{array}$ & $15(5.8)$ & $1(0.4)$ \\
\hline $\begin{array}{l}\text { Voluntary retirement because of the } \\
\text { disease }\end{array}$ & $21(8.1)$ & $6(2.3)$ \\
\hline $\begin{array}{l}\text { Dismissal (closure of business) because } \\
\text { of the disease }\end{array}$ & $11(4.2)$ & $0(0.0)$ \\
\hline Mandatory retirement & $23(8.9)$ & $12(4.6)$ \\
\hline Unemployed & $11(4.2)$ & $6(2.3)$ \\
\hline Others & $15(5.8)$ & $4(1.5)$ \\
\hline
\end{tabular}

course of disease and confirmed that the distress of spouses or partners significantly correlated with that of patients. Then, they indicated that the mental distress of spouses or partners gradually increases after diagnosis and becomes more strongly correlated with that of patients. Because currently treated patients and spouses of such patients accounted for $50 \%$ of the subjects in the present study, the degree of difficulty perceived by the spouses might not have been as high as that of difficulty perceived by the patients. However, we assume that the degree of "difficulty in seeking expert advice on the disease state and treatment" in the spouses was as high as that in the patients because spouses were greatly involved in treatment of patients soon after diagnosis.

\section{Difficulty perceived by the young spouses}

In the young subgroup, the degree of difficulty perceived by the spouses was as high as that of difficulty perceived by the patients for all subcategories except "difficulty in adapting to changes in the social environment (I feel that my appearance has changed or that I am treated differently)." People aged 39 years or younger, who were classified as the younger generation in the present study, are called "adolescents and young adults (AYA)." Cancer 
Table 3 Differences in difficulty between the patients and spouses (patients, $n=259$; spouses, $n=259$ )

\begin{tabular}{|c|c|c|c|c|c|c|}
\hline & Patie & & Spous & & & \\
\hline & M & SD & M & SD & $t$ & $p$ \\
\hline 1. Difficulty in performing activities of daily living & 2.14 & .74 & 1.80 & .66 & 5.48 & $.00^{*}$ \\
\hline 2. Difficulty in seeking expert advice on the disease state and treatment & 1.87 & .82 & 1.82 & .68 & .75 & .45 \\
\hline 3. Complaint with health care providers & 1.89 & .81 & 1.71 & .66 & 2.67 & $.01^{*}$ \\
\hline 4. Lack of information on treatment and disease state & 1.99 & .80 & 1.76 & .70 & 3.40 & $.00^{*}$ \\
\hline 5. Lack of information on self-care & 2.02 & .86 & 1.77 & .76 & 3.45 & $.00^{*}$ \\
\hline 6. Conflict over family relationships & 1.88 & .82 & 1.72 & .70 & 2.36 & $.02^{*}$ \\
\hline 7. Concerns for family members & 2.04 & .80 & 1.86 & .70 & 2.72 & $.01^{*}$ \\
\hline 8. Difficulty in planning life & 2.04 & .85 & 1.78 & .76 & 3.67 & $.00^{*}$ \\
\hline 9. Conflict over relationships with non-family members & 1.92 & .82 & 1.71 & .79 & 3.03 & $.00^{*}$ \\
\hline 10. Difficulty in adapting to changes in the social environment & 2.05 & .80 & 1.68 & .73 & 5.46 & $.00^{*}$ \\
\hline 11. Lack of local support services & 2.08 & .92 & 1.81 & .84 & 3.47 & $.00^{*}$ \\
\hline 12. Difficulty in solving work-related issues & 1.84 & .85 & 1.67 & .73 & 2.41 & $.02^{*}$ \\
\hline 13. Difficulty in making financial arrangements & 2.16 & .90 & 1.87 & .81 & 3.86 & $.00^{*}$ \\
\hline 14. Lack of information on welfare services available during treatment & 1.80 & .91 & 1.63 & .76 & 2.31 & $.02^{*}$ \\
\hline
\end{tabular}

patients in the AYA generation experience, after diagnosis and treatment, not only difficulties associated with social relationships, work, academic background, property, etc., but also many physical and psychosocial problems, such as interruptions to romantic and/or intimate relationships, reconsideration of family planning, infertility, and body image dissatisfaction $[19,20]$. For this reason, young caregivers in this generation often seem to feel burdened [21, 22] and to perceive a high degree of difficulty.

\section{Difficulty perceived by female spouses}

For the combination of a male patient and a female spouse, the degree of difficulty perceived by the spouses was as high as that of difficulty perceived by the patients for "difficulty in seeking expert advice on the disease

Table 4 Differences in difficulty between the patients and spouses in the adolescents' and young adults' generation (patients, $\mathrm{n}=55$; spouses, $n=55)$

\begin{tabular}{|c|c|c|c|c|c|c|}
\hline & Patie & & Spou & & & \\
\hline & M & SD & M & SD & $t$ & $p$ \\
\hline 1. Difficulty in performing activities of daily living & 2.37 & .88 & 2.21 & .84 & .94 & .35 \\
\hline 2. Difficulty in seeking expert advice on the disease state and treatment & 2.07 & 1.06 & 2.18 & .82 & -.64 & .53 \\
\hline 3. Complaints with health care providers & 2.08 & 1.02 & 2.10 & .75 & -.90 & .93 \\
\hline 4. Lack of information on treatment and disease state & 2.17 & 1.02 & 2.10 & .84 & .41 & .68 \\
\hline 5. Lack of information on self-care & 2.26 & 1.10 & 2.08 & .90 & .92 & .36 \\
\hline 6. Conflict over family relationships & 2.09 & .99 & 2.06 & .89 & .15 & .88 \\
\hline 7. Concerns for family members & 2.26 & .92 & 2.22 & .80 & .26 & .80 \\
\hline 8. Difficulty in planning life & 2.57 & .96 & 2.31 & 1.00 & 1.41 & .16 \\
\hline 9. Conflict over relationships with non-family members & 2.24 & .99 & 2.10 & .95 & .79 & .43 \\
\hline 10. Difficulty in adapting to changes in the social environment & 2.42 & .95 & 1.95 & .91 & 2.67 & .01 \\
\hline 11. Lack of local support services & 2.30 & 1.10 & 2.19 & .94 & .53 & .60 \\
\hline 12. Difficulty in solving work-related issues & 2.17 & 1.03 & 2.12 & .91 & .26 & .80 \\
\hline 13. Difficulty in making financial arrangements & 2.44 & .93 & 2.22 & .95 & 1.22 & .23 \\
\hline 14. Lack of information on welfare services available during treatment & 1.99 & 1.09 & 1.93 & .94 & .34 & .73 \\
\hline
\end{tabular}


Table 5 Differences in difficulty between male patients and female spouses (patients, $n=128$; spouses, $n=128$ )

\begin{tabular}{|c|c|c|c|c|c|c|}
\hline & \multicolumn{2}{|c|}{ Patients } & \multicolumn{2}{|c|}{ Spouses } & \multirow[b]{2}{*}{$t$} & \multirow[b]{2}{*}{$p$} \\
\hline & M & SD & M & SD & & \\
\hline 1. Difficulty in performing activities of daily living & 2.15 & .78 & 1.75 & .70 & 4.34 & $.00^{*}$ \\
\hline 2. Difficulty in seeking expert advice on the disease state and treatment & 1.84 & .80 & 1.81 & .72 & .33 & .74 \\
\hline 3. Complaints with health care providers & 1.86 & .81 & 1.70 & .70 & 1.70 & .09 \\
\hline 4. Lack of information on treatment and disease state & 1.94 & .79 & 1.77 & .77 & 1.81 & .07 \\
\hline 5. Lack of information on self-care & 1.92 & .86 & 1.79 & .83 & 1.26 & .21 \\
\hline 6. Conflict over family relationships & 1.88 & .82 & 1.73 & .70 & 1.60 & .11 \\
\hline 7. Concerns for family members & 2.06 & .79 & 1.88 & .74 & 1.84 & .07 \\
\hline 8. Difficulty in planning life & 2.05 & .83 & 1.76 & .74 & 2.99 & $.00^{*}$ \\
\hline 9. Conflict over relationships with non-family members & 1.91 & .80 & 1.62 & .79 & 2.99 & $.00^{*}$ \\
\hline 10. Difficulty in adapting to changes in the social environment & 2.04 & .87 & 1.66 & .79 & 3.65 & $.00^{*}$ \\
\hline 11. Lack of local support services & 1.98 & .88 & 1.82 & .91 & 1.52 & .13 \\
\hline 12. Difficulty in solving work-related issues & 1.94 & .86 & 1.66 & .70 & 2.90 & $.00^{*}$ \\
\hline 13. Difficulty in making financial arrangements & 2.24 & .93 & 2.01 & .92 & 1.96 & .05 \\
\hline 14. Lack of information on welfare services available during treatment & 1.80 & .91 & 1.66 & .82 & 1.30 & .19 \\
\hline
\end{tabular}

state and treatment (lack of opportunities to consult for patient transfer arrangement, hospital selection, second opinion, psychological counseling, etc.)," "complaint with health care providers," "lack of information on treatment and disease state," "lack of information on self-care (lack of knowledge on nutritional needs of patients or how to deal with anxiety)," "concerns for family members," "lack of local support services," "difficulty in making financial arrangements," and "lack of information on welfare services available during treatment (lack of knowledge on the nursing-care insurance system or nursing-care facilities and equipment)." Generally, compared to men who take care of their wives with cancer, women who take care of their husbands with cancer have higher mental morbidity (high levels of distress, depression, and anxiety, and a low level of mental health), physical morbidity (low physical health score, decreased physical function, and loss of physical fitness), and social morbidity (low satisfaction in marriage and limited social support) [12, 23, 24]. Ussher et al. [25] attributed this to the fact that women caregivers are positioned as all-encompassing expert careers, expected to be competent at decision-making, a range of physical caring tasks, and provision of emotional support for the person with cancer. The consequences of this positioning are over-responsibility and self-sacrifice, physical costs and overwhelming emotions. Men caregivers positioned caring as a competency task which they had mastered, and which provided them with satisfaction.

\section{Limitations}

The present study has several limitations. First, the results may have been affected by measurement bias because of the use of data from internet-based surveys. Data reliability is limited by the facts that the participants in these surveys determined whether they met the eligibility criteria and that data on diagnosis, treatment regimens, etc., were self-reported. Thus, in future studies, more accurate medical data need to be collected by conducting questionnaire or interview surveys at medical institutions in combination with review of medical records. However, a merit of an internet-based survey is that it guarantees anonymity and allows participants to respond without worrying about health care providers. Second, because of arrangements for this study and funding issues, several years passed between the patient and spouse surveys, and we were unable to collect data from patient-and-spouse pairs. These facts may also have contributed to measurement bias. The degree of social difficulties differed between the patients and spouses in the present study because both groups might have had different underlying problems. Thus, in future studies, patient-and-spouse pairs need to be targeted and surveyed around the same time. However, in this study, comparison was made while the differences in background problems were minimized as much as possible by matching propensity scores for data on sex, age group, and presence or absence of recurrence. Third, an analysis of non-responder or cancer patients who did not experience social difficulties is key to gaining information about a possible sample bias that might impact study results. This was not done in this study. Fourth, an unstandardized scale was used in this study. That is why we prepared the scale using the $\mathrm{KJ}$ method and confirmed the reliability with an $\alpha$ coefficient. 


\section{Conclusions}

Health care providers should show sufficient concern for both patients and their spouses, particularly young and female spouses. In other words, it was considered important to change the approach method based on age and sex, and to intervene at the time of diagnosis rather than when the cancer was more advanced.

\section{Abbreviation}

AYA: Adolescents and young adults

\section{Acknowledgements}

The authors want to thank all cancer patients and their spouses who participated in this study.

\section{Funding}

The authors received no financial support for the research, authorship, and/or publication of this article.

\section{Availability of date and materials}

The datasets used and/or analyzed during the current study are available from the corresponding author on reasonable request.

\section{Authors' contributions}

Data were collected by $\mathrm{KA}, \mathrm{WT}, \mathrm{KH}$, analyzed by $\mathrm{Kl}$, and interpreted by $\mathrm{TT}$ and $\mathrm{KI}$. The work was drafted by $\Pi \mathrm{T}$ and $\mathrm{Kl}$, and the manuscript was reviewed and edited by $\Pi$ and $\mathrm{Kl}$. All authors read and approved the final manuscript.

\section{Ethics approval and consent to participate}

While this study is a secondary analysis using composite data from surveys on social problems of patients and their spouses, each survey was approved by the Ethics Committee of Tokyo Medical and Dental University Medical Hospital.

\section{Competing interests}

The authors declare that they have no competing interests.

\section{Publisher's Note}

Springer Nature remains neutral with regard to jurisdictional claims in published maps and institutional affiliations.

\section{Author details}

'Section of Psychiatry and Behavioral Sciences, Graduate School of Medical and Dental Sciences, Tokyo Medical and Dental University, 1-5-45 Yushima, Bunkyo-ku, Tokyo 113-8519, Japan. 'Section of Liaison Psychiatry and Palliative Medicine, Graduate School of Medical and Dental Sciences, Tokyo Medical and Dental University, Tokyo, Japan. ${ }^{3}$ Graduate School of Human Sciences, Waseda University, Saitama, Japan. ${ }^{4}$ Department of Medical Oncology, Kanazawa Medical University, Ishikawa, Japan. ${ }^{5}$ Department of Health Science, School of Allied Health Sciences, Kitasato University, Kanagawa, Japan.

Received: 29 December 2017 Accepted: 28 May 2018

Published online: 08 June 2018

\section{References}

1. Wright EP, Kiely MA, Lynch $\mathrm{P}$, et al. Social problems in oncology. $\mathrm{Br}$ Cancer. 2002;87:1099-104.

2. Muzzatti B, Annunziata MA. Assessing the social impact of cancer: a review of available tools. Support Care Cancer. 2012;20:2249-57.

3. Duijts SF, van Eqmond MP, Spelten E, et al. Physical and psychosocial problems in cancer survivors beyond return to work: a systematic review. Psychooncology. 2014;23:481-92.

4. Yabroff KR, Dowling EC, Guy GP Jr, et al. Financial hardship associated with cancer in the United States: findings from a population based sample of adult cancer survivors. J Clin Oncol. 2016:34:259-67.

5. Catt S, Starkings R, Shilling V, Fallowfield L. Patient-reported outcome measures of the impact of cancer on patients' everyday lives: a systematic review. J Cancer Surviv. 2017;11:211-32.
6. Cull A, Stewart M, Altman DG. Assessment of and intervention for psychosocial problems in routine oncology practice. Br J Cancer. 1995;72:229-35.

7. Kobayashi K, Morita S, Shimonagayoshi M, et al. Effects of socioeconomic factors and cancer survivors' worries on their quality of life (QOL) in Japan. Psychooncology. 2008;17:606-11.

8. Dapueto JJ, Servente L, Francolino C, Hahn EA. Determinants of quality of life in patients with cancer. Cancer. 2005;103:1072-81.

9. Hisamura K, Matsushima E, Tsukayama S, et al. An exploratory study of Soc Probl experienced by ambulatory cancer patients in Japan: Frequency and association with perceived need for help. Psychooncology. 2018; https://doi. org/10.1002/pon.4703. Epub ahead of print

10. Wright $P$, Downing A, Morris EJ, et al. Identifying social distress: a crosssectional survey of social outcomes 12 to 36 months after colorectal cancer diagnosis. J Clin Oncol. 2015;33:3423-30.

11. Siegel K, Raveis VH, Houts $P$, Mor V. Caregiver burden and unmet patient needs. Cancer. 1991;68:1131-40.

12. Li QP, Mak YW, Loke AY. Spouses' experience of caregiving for cancer patients: a literature review. Int Nurs Rev. 2013;60:178-87.

13. Rhee YS, Yun YH, Park S, et al. Depression in family caregivers of cancer patients: the feeling of burden as a predictor of depression. J Clin Oncol. 2008;26:5890-5.

14. Hisamura K. Problems in social lives cancer patients experience and the importance of social support. Gendai no Esupuri. 2010;517:41-53. (in Japanese)

15. Kawakita J. Hassoho [Aboduction]. Tokyo: Chuokoron-Shinsha; 1967. (in Japanese)

16. Kawakita J. Zoku Hassoho [Aboduction: part two]. Tokyo: Chuokoron-Shinsha; 1970. (in Japanese)

17. Hagedoom M, Sanderman R, Bolks HN, et al. Distress in couples coping with cancer: a meta-analysis and critical review of role and gender effects. Psychol Bull. 2008;134:1-30.

18. Hodges $L$, Humphris $G M$, Macfarlane $G$. A meta-analytic investigation of the relationship between the psychological distress of cancer patients and their carers. Soc Sci Med. 2005;60:1-12.

19. Quinn GP, Goncalves V, Sehovic I, et al. Quality of life in adolescent and young adult cancer patients: a systematic review of the literature. Patient Relat Outcome Meas. 2015;6:19-51.

20. Leuteritz K, Friedrich M, Nowe E, et al. Life situation and psychosocial care of adolescent and young adult (AYA) cancer patients - study protocol of a 12-month prospective longitudinal study. BMC Cancer. 2017;17:82

21. Payne S, Smith P, Dean S. Identifying the concerns of informal carers in palliative care. Palliat Med. 1999:13:37-44.

22. Siminoff LA, Wilson-Genderson M, Baker S Jr. Depressive symptoms in lung cancer patients and their caregivers and the influence of family environment. Psychooncology. 2010;19:1285-93.

23. Li Q, Loke AY. A spectrum of hidden morbidities among spousal caregivers for patients with cancer, and differences between the genders: a review of the literature. Eur J Oncol Nurs. 2013;17:578-87.

24. Moser MT, Kunzler A, Nussbeck F, et al. Higher emotional distress in female partners of cancer patients: prevalence and patient-partner interdependencies in a 3-year cohort. Psychooncology. 2013;22:2693-701.

25. Ussher JM, Sandoval M. Gender differences in the construction and experience of cancer care: the consequences of the gendered positioning of cares. Psychol Health. 2008;23:945-63.

Ready to submit your research? Choose BMC and benefit from

- fast, convenient online submission

- thorough peer review by experienced researchers in your field

- rapid publication on acceptance

- support for research data, including large and complex data types

- gold Open Access which fosters wider collaboration and increased citations

- maximum visibility for your research: over $100 \mathrm{M}$ website views per year

At BMC, research is always in progress.

Learn more biomedcentral.com/submissions 